\title{
Ileocecal duplication cysts: Is the loss of the valve always necessary?
}

\author{
Pieralba Catalano*, Maria Rita Di Pace, Anna Maria Caruso, Enrico De Grazia, Marcello Cimador \\ Pediatric Surgical Unit, Department of Mother and Child Care, University of Palermo, Palermo, Italy
}

\section{A R T I C L E I N F O}

\section{Article history:}

Received 13 November 2013

Received in revised form 28 November 2013

Accepted 25 December 2013

\section{Key words:}

Enteric duplication

Ileocecal resection

Ileocecal valve/junction

\begin{abstract}
A B S T R A C T
Background: Ileocecal (IC) duplication cysts are enteric duplications located at the IC junction, not clearly identified in all the published series. The reported treatment is IC resection and ileocolic anastomosis. It is well known that the loss of the IC valve has several adverse effects. This study is aimed at demonstrating that cyst removal together with the common ileal wall and following enterorrhaphy is possible, safe, and effective in preserving the IC region.

Methods: Medical records of 3 patients who underwent surgery for IC duplication between 2003 and 2013 were retrospectively reviewed evaluating follow-up results.

Results: All patients had an antenatal diagnosis of intraabdominal cystic mass. In two cases associated malformations were reported. The lesions presented at newborn age with intermittent small bowel obstruction and required removal. No patients underwent IC resection. The diagnosis of duplication cyst was confirmed by histo-pathologic examination. The postoperative course was uneventful, even in the long-term follow-up.

Conclusions: Our conservative approach is a simple and safe technique, effective in avoiding the loss of the IC valve in children with duplication at the IC junction.
\end{abstract}

(c) 2014 Elsevier Inc. All rights reserved.
Ileocecal (IC) duplication cysts are intestinal duplications located at the IC junction, usually unacknowledged in reported series. Enteric duplications are rare congenital diseases, accounting for 1 case per 18000 live births [1] and arising at any level of the gastrointestinal tract, but most commonly at the small intestine [2]. It is now widely accepted that these lesions must be removed after being diagnosed, because they usually develop serious complications as bowel obstruction secondary to adjacent pressure or mass effect, intussusception, gastrointestinal bleeding or perforation and more rarely volvulus and associated malignancy, especially in adults with lesions of the colon [3]. Most of the intestinal duplications share a common muscular wall and blood supply with the native bowel, especially those located in the abdomen, where they lie in the mesenteric border. Therefore, the preferred treatment is total cyst excision with resection of the adjacent segment. However, when feasible, cyst excision alone may be rarely carried out [4].

To our knowledge, the cases of IC duplications reported in the literature have been all treated with IC resection and ileocolic anastomosis. The importance of the IC valve has been well known for a long time. The aim of our study was to report the safety and efficacy of a conservative operative technique in children with duplication cyst at the IC junction, in order to preserve the IC region.

\footnotetext{
* Corresponding author at: University of Palermo, Department of Mother and Child Care, Pediatric Surgical Unit, Alfonso Giordano 3, Palermo 90100, Italy.

E-mail address: pieralba.catalano@libero.it (P. Catalano).
}

\section{Materials and methods}

A retrospective review of the medical records of all patients, who underwent surgical treatment for intraabdominal enteric duplication cyst between 2003 and 2013, was carried out. All three patients with duplication cyst at the IC junction were included in our study. The described technique was applied to all cases. The procedure was performed through a transverse supraumbilical laparotomy. The last ileal loop appeared slightly dilated and the colon was empty. The duplications, located at the IC angle in the mesenteric border, were cystic with a maximum diameter between 3 and $5 \mathrm{~cm}$; they shared a thin smooth muscular wall with the terminal ileum, close to the valve, and compressed the cecum, flattening it (Fig. 1A). In the first case the cecal rim was not clearly evident, so a cecal enterotomy was performed, in order to rule out an involvement of the cecum and to better visualize the IC valve. The enterotomy was unnecessary in the other two cases. After dissection of the mesenteric sheet above the lesion and mobilization of the cyst from the cecal wall, the cyst was gradually enucleated up to the common wall with the native ileum (Fig. 1B). The shared wall was circumferentially incised, starting from the proximal edge in order to avoid injury of the IC valve, and then removed together with the duplication (Fig. 1C). The excision was closed in a transverse fashion with interrupted 5.0 monofilament polyglycolic absorbable suture, the small mesenteric defect was sutured and appendectomy was performed; the cecal enterotomy was closed also in the first case (Fig. 1D). The postoperative course was analysed. Children were evaluated in clinical follow-up examinations at 1, 3,6 and 12 months of age. 


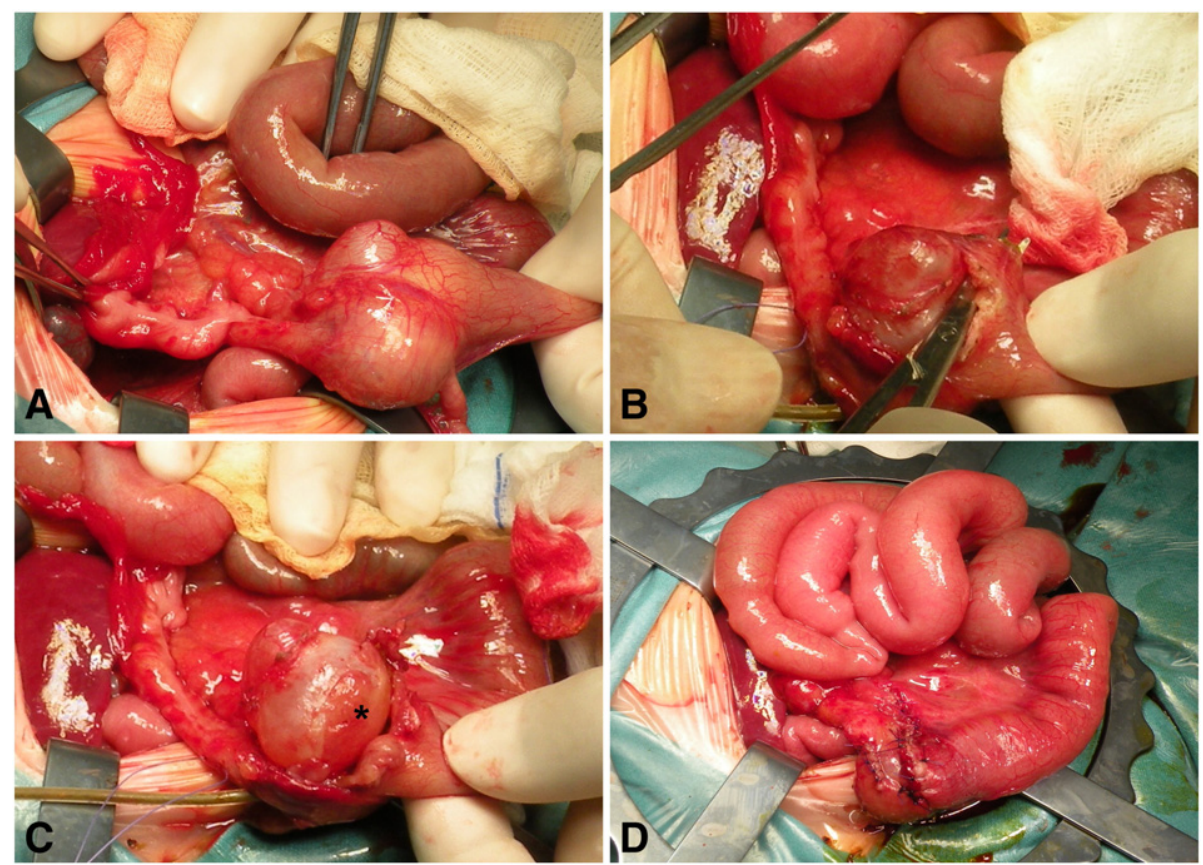

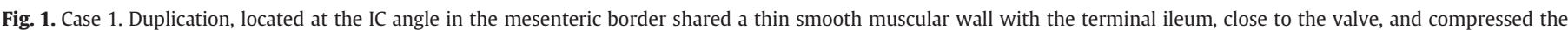

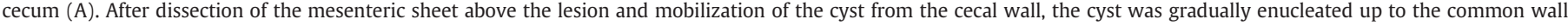

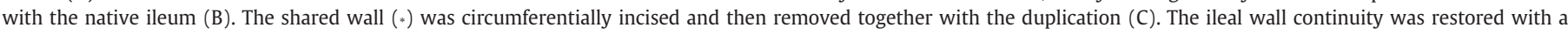

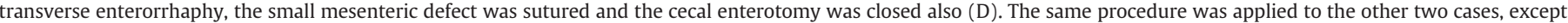
for the cecal enterotomy.

\section{Results}

All cases (Table 1 ) were surgically treated at newborn age. Of the 3 patients with ileocecal duplication cyst, 2 were boys and 1 was a girl; they were born at term by vaginal delivery. All cases had an antenatal diagnosis of abdominal cystic mass (choledocal cyst, mesenteric cyst and ovarian cyst), but in none of our patients an intestinal duplication was suspected. First prenatal detection of the cysts was at 2038 weeks of gestational age. The two male patients had associated malformations: one patient had rectoperineal fistula, that required anoplasty at birth, the other patient had monolateral cryptorchidism, treated at 19 months of age. In all patients IC duplication early presented with intermittent small bowel obstruction, requiring laparotomy during the first month of life, at 3,14 and 16 days of age, respectively. The mean operating time was 105 min (range 100$110 \mathrm{~min}$ ). Oral feeding was started on postoperative day 6 . The mean hospital stay was 9 days (range 8-10 days). The postoperative period was uneventful. The diagnosis of duplication cyst was made by histopathologic examination, that showed intestinal mucosal lining in all cases. At follow-up examinations, children had normal height and weight growth and parents referred regular bowel movements and denied any problem.

\section{Discussion}

Duplications at the IC junction are a particular entity, not clearly identified in all the reported series [5-8] and generally included into the ileal duplications [9]. Only few Authors described the IC type, for which the operative approach consisted of segmental resection with primary reanastomosis $[10,11]$. In particular, Puligandla et al. examined the duplications found in the IC valve region as an independent entity from the duplications found in the ileum and described a frequency of $30.2 \%$ and $31.5 \%$ respectively, reporting the largest series. However, in this review the clinical data were brought together and the surgical treatment was briefly described as resection with or without intestinal anastomosis, not specifically referring to the site of the malformation [12].

In another study of antenatally detected abdominal enteric duplications, all the lesions of the ileum ( 9 cases) were defined as IC; however, the resection of the IC junction with duplication and ileocolic anastomosis was performed only in 3 cases, instead the removal of ileal segment with duplication and ileo-ileal anastomosis was carried out in the remaining cases, except for one patient in whom it was possible to resect the cyst alone. So it seems that the true lesions of the IC region are those in which it was

Table 1

Clinical and operative data of our patients with IC duplication cyst.

\begin{tabular}{|c|c|c|c|c|c|c|c|c|c|}
\hline $\begin{array}{l}\text { Patient } \\
\text { no. }\end{array}$ & Sex & $\begin{array}{l}\text { Prenatal } \\
\text { diagnosis }\end{array}$ & $\begin{array}{l}\text { Associated } \\
\text { malformations }\end{array}$ & Complaints & $\begin{array}{l}\text { Preoperative } \\
\text { diagnosis }\end{array}$ & $\begin{array}{l}\text { Age at } \\
\text { surgery }\end{array}$ & $\begin{array}{l}\text { Location of } \\
\text { duplication cyst }\end{array}$ & Surgery & Follow-up \\
\hline 1 & $\mathrm{~F}$ & Ovarian cyst & - & $\begin{array}{l}\text { Recurrent } \\
\text { vomiting }\end{array}$ & $\begin{array}{l}\text { Intraabdominal } \\
\text { cystic mass }\end{array}$ & $16 \mathrm{~d}$ & $\begin{array}{l}\text { Ileocecal angle in the } \\
\text { mesenteric border }\end{array}$ & $\begin{array}{l}\text { Cyst removal together with the } \\
\text { common ileal wall and following } \\
\text { enterorrhaphy + suture } \\
\text { of cecal enterotomy }\end{array}$ & Uneventful \\
\hline 2 & M & $\begin{array}{l}\text { Mesenteric } \\
\text { cyst }\end{array}$ & $\begin{array}{l}\text { Rectoperineal } \\
\text { fistula }\end{array}$ & $\begin{array}{l}\text { Intermittent } \\
\text { constipation }\end{array}$ & $\begin{array}{l}\text { Mesenteric vs } \\
\text { duplication cyst }\end{array}$ & $14 \mathrm{~d}$ & $\begin{array}{l}\text { Ileocecal angle in the } \\
\text { mesenteric border }\end{array}$ & $\begin{array}{l}\text { Cyst removal together with the } \\
\text { common ileal wall and following } \\
\text { enterorrhaphy }\end{array}$ & Uneventful \\
\hline 3 & M & $\begin{array}{l}\text { Choledocal } \\
\text { cyst }\end{array}$ & $\begin{array}{l}\text { Left } \\
\text { cryptorchidism }\end{array}$ & $\begin{array}{l}\text { Vomiting, } \\
\text { abdominal } \\
\text { distension }\end{array}$ & Duplication cyst & $3 d$ & $\begin{array}{l}\text { Ileocecal angle in the } \\
\text { mesenteric border }\end{array}$ & $\begin{array}{l}\text { Cyst removal together with the } \\
\text { common ileal wall and following } \\
\text { enterorrhaphy }\end{array}$ & Uneventful \\
\hline
\end{tabular}


necessary to perform a more extensive resection with loss of the valve [13].

Summarizing the literature data, IC duplications are more frequently cystic lesions of varying size, share a common blood supply and wall with the ileum for a few centimeters from the valve and compress the cecum. These malformations manifest a clinical picture usually characterized by early presentation, occlusive feature and potentially deadly outcome for undiagnosed infants $[14,15]$. In our series, the IC duplication cysts manifested very early, with a clinical picture of intermittent small bowel obstruction because of their proximity to the IC valve, which resulted in partial obstruction by the cystic mass. An early diagnosis, together with a timely surgical treatment, is fundamental in these cases, in order to avoid the onset of complications with increasing mortality. Nowadays antenatal ultrasound is an effective tool in diagnosing the abdominal cystic masses; all our three cases had a prenatal suspicion, confirmed at birth. This allowed us to relate nonspecific symptoms as recurrent vomiting and intermittent constipation with the imaging data and to schedule surgery at newborn age. Contrary to the other cystic ileal duplications and similar to more rare lesions of the cecum, the reported cases of duplication at the IC junction were treated with an extensive intestinal resection that implies the loss of the IC valve because of their anatomical configuration.

Different studies have demonstrated that resection of the IC region has several adverse effects.

IC valve or better IC junction is a transition zone regulating intestinal transit from the small bowel into the colon. By slowing the passage of nutrients from the ileum, the IC valve helps to prolong intestinal transit time, thereby increasing the time that nutrients are in contact with the mucosal surface and then maximizing the absorption of nutrients, fluids and electrolytes. It also blocks the waste materials from backing back up into the small intestine. Removal of the IC valve can lead to bacterial overgrowth, reduced intestinal transit time and finally impaired absorption with symptoms like diarrhea, malnutrition, and electrolyte imbalance [16,17]. The importance of the valve in children who underwent extensive bowel resection is well known in the literature [18], but there are a few data regarding the role of the loss of the valve in children with a normal intestinal length.

A follow-up study, conducted in 5 neonates and 3 infants who underwent IC resection, showed that all patients had moderate diarrhea until 6 years of age, whereas no patient of the control ileal resection group had diarrhea after 2 years of age. Nevertheless, no significant differences were noted in nutritional status, hematology and serum biochemistry (protein metabolism, lipid metabolism, bile acid, and vitamin B12) data between the two groups, but the limitation of this study is represented by the very small number of patients [19]. Folaranmi et al. in a recent paper investigated the importance of the IC valve in 62 children ( 26 limited hemicolectomies, 27 hemicolectomies and 13 terminal ileum resections) not suffering from short bowel syndrome or Crohn's disease. They stated that chronic diarrhea is a significant complication after limited hemicolectomy and is likely to originate from the loss of the IC valve itself rather than the loss of the ileal or colonic segment [20]. Therefore, in non-tumoral lesions, preservation of the IC region to retain its important function should be considered, especially in pediatric age.

In our experience we were successful in preserving the IC region in all patients with IC duplication, performing a total excision of the lesion together with the common wall between the cyst and ileum. The ileal wall continuity was restored with a transverse enterorrhaphy, in order to prevent the onset of bowel stenosis. None of our patients reported complications, even in the long-term follow-up. However, the use of our technique could be limited in the case of very large cysts or tubular duplications, because they would result in a parietal ileal defect difficult to repair with an enterorrhaphy, and the weakness of our study is represented by the small number of studied patients, that is justified by the rarity of this malformation.

In conclusion, this conservative technique is simple, safe and effective in avoiding the loss of the IC valve in children with duplication cyst at the IC junction. We think that it should be always considered before performing an ileocecal resection with ileocolic anastomosis in cases of IC duplication. Moreover, duplications at the IC junction should be distinguished from other ileal duplications, because of their anatomical and clinical characteristics. Finally, our paper confirms that radical surgery should not be carried out, unless absolutely necessary, while new attempts of conservative surgery should be promoted.

\section{References}

[1] Potter EL. Pathology of the fetus and newborn. Chicago: Year Book Medical Publishers; 1961.

[2] Stringer MD, Spitz L, Abel R, et al. Management of alimentary tract duplication in children. Br J Surg 1995;82:74-8.

[3] Otter MI, Marks CG, Cook MG. An unusual presentation of intestinal duplication with a literature review. Dig Dis Sci 1996;41:627-9.

[4] Land DP. Alimentary tract duplications. In: Grosfeld JL, O’Neill JA, Fonkalsrud EW, Coran AG, editors. Pediatric surgery. 6th ed. Philadelphia: Mosby-Elsevier; 2006. p. 1389-98.

[5] Stern LE, Warner BW. Gastrointestinal duplications. Semin Pediatr Surg 2000;9: $135-40$.

[6] Wrenn EL, Hollabaugh RS. Duplications of the digestive tract. In: Ashcraft KW, Murphy JP, Sharp RJ, et al, editors. Pediatric surgery. Philadelphia (Pa): WB Sounders; 2000. p. 556-67.

[7] Iyer CP, Mahour GH. Duplications of the alimentary tract in infants and children. J Pediatr Surg 1995;30:1267-70.

[8] Holcomb GW, Gheissari A, O'Neill Jr JA, et al. Surgical management of alimentary tract duplications. Ann Surg 1989;209:167-74.

[9] Laje P, Flake AW, Adzick NS. Prenatal diagnosis and postnatal resection of intraabdominal enteric duplications. J Pediatr Surg 2010;45:1554-8.

[10] Ildstad ST, Tollerud DJ, Weiss RG, et al. Duplications of the alimentary tract. Clinical characteristics, preferred treatment, and associated malformations. Ann Surg 1988;208:184-9.

[11] Bower RJ, Sieber WK, Kiesewetter WB. Alimentary tract duplications in children. Ann Surg 1978;188:669-74.

[12] Puligandla PS, Nguyen LT, St-Vil D, et al. Gastrointestinal duplications. J Pediatr Surg 2003;38:740-4.

[13] Foley PT, Sithasanan N, McEwing R, et al. Enteric duplications presenting as antenatally detected abdominal cysts: is delayed resection appropriate? J Pediatr Surg 2003;12:1810-3.

[14] Kibayashi K, Sumida T, Shojo $\mathrm{H}$, et al. Unexpected death due to intestinal obstruction by a duplication cyst in an infant. Forensic Sci Int 2007;173:175-7.

[15] Kashiwagi Y, Suzuki S, Watanabe K, et al. Sudden unexpected death associated with ileocecal duplication cyst and clinical review. Clin Med Insights Pediatr 2010;4:25-8.

[16] Malbert CH. The ileocolonic sphincter. Neurogastroenterol Motil 2005;17(Suppl 1):41-9.

[17] Shafik AA, Ahmed IA, Shafik A, et al. Ileocecal junction: anatomic, histologic, radiologic and endoscopic studies with special reference to its antireflux mechanism. Surg Radiol Anat 2011;33:249-56.

[18] Dorney SF, Ament ME, Berquist WE, et al. Improved survival in very short small bowel of infancy with use of long-term parenteral nutrition. J Pediatr 1985;107: 521-5.

[19] Iwanaka T, Hashizume K, Kawarasaki H, et al. Ileocecal resection in neonates and infants: a follow-up study. J Pediatr Surg 1993;28:110-2.

[20] Folaranmi S, Rakoczy G, Bruce J, et al. Ileocaecal valve: how important is it? Pediatr Surg Int 2011;27:613-5 